therapy experienced significantly less flares during pregnancy [aOR 0.18 (95\%Cl: 0.09-0.38), $p=0.013$.

Conclusion: In our cohort, SLE women with additional risk factors achieved a favourable pregnancy outcome. This encouraging result is in part attributable to pregnancy counselling with the advice to continue HCQ throughout gestation. Disclosure of Interests: Isabell Haase Grant/research support from: Abbvie, Medac, Hexal, Pfizer, Ralph Brinks: None declared, Matthias Schneider Grant/ research support from: GSK, UCB, Abbvie, Consultant of: Abbvie, Alexion, Astra Zeneca, BMS, Boehringer Ingelheim, Gilead, Lilly, Sanofi, UCB, Speakers bureau: Abbvie, Astra Zeneca, BMS, Chugai, GSK, Lilly, Pfizer, Sanofi, Rebecca Fischer-Betz Consultant of: UCB, Speakers bureau: Abbvie, Amgen, Biogen, BMS, Celgene, Chugai, GSK, Janssen, Lilly, Medac, MSD, Novartis, Roche, UCB, Pfizer.

DOI: 10.1136/annrheumdis-2020-eular.3567

\section{AB0376 DETERMINANTS AND PROTECTIVE EFFECTS OF A LOW DISEASE ACTIVITY STATE IN SYSTEMIC LUPUS ERYTHEMATOSUS: RESULTS FROM A PROSPECTIVE CHINESE COHORT}

Y. Hao ${ }^{1}$, L. Ji ${ }^{1}$, D. Gao ${ }^{1}$, Y. Fan ${ }^{1}$, E. F. Morand ${ }^{2}$, M. Nikpour ${ }^{3,4}$, Z. Zhang ${ }^{1}$. ${ }^{1}$ Peking University First Hospital, Rheumatology and Clinical Immunology, Beijing, China; ${ }^{2}$ Monash University, Medicine, Melbourne, China; ${ }^{3}$ St. Vincent's Hospital, Rheumatology, Melbourne, Australia; ${ }^{4}$ University of Melbourne, Medicine, Melbourne, Australia

Background: The concept of treat to target in systemic lupus erythematosus has moved forward in recent years. The Lupus low disease activity state (LLDAS) defined by the Asia-Pacific Lupus Collaboration (APLC) in 2016 has been validated prospectively in the APLC cohort itself and retrospectively in multiple other cohorts.

Objectives: The concept of treat to target in systemic lupus erythematosus has moved forward in recent years. The Lupus low disease activity state (LLDAS) defined by the Asia-Pacific Lupus Collaboration (APLC) in 2016 has been validated prospectively in the APLC cohort itself and retrospectively in multiple other cohorts. The aim of this study was to investigate the frequency and determinants of achieving LLDAS, and the influence of LLDAS on short term outcomes including disease flare and damage accrual in Chinese lupus patients.

\begin{tabular}{lllllll}
\hline \multicolumn{5}{c}{ Table 1-Determinants of achieving LLDAS for at least } \\
univariate and multivariate logistic regression analysis
\end{tabular}

Table 2 -Determinants of disease flare by univariate and multivariate Cox regression analysi\$

\begin{tabular}{|c|c|c|c|c|c|c|}
\hline \multirow[b]{2}{*}{ Variables } & \multicolumn{3}{|c|}{ Univariate analysis } & \multicolumn{3}{|c|}{ Multivariate analysis } \\
\hline & $\mathrm{HR}^{\mathrm{H}}$ & $95 \% \mathrm{Cl}$ & Pvalue & $\mathrm{HR}^{\mathrm{T}}$ & $95 \% \mathrm{Cl}$ & Pvalue \\
\hline Gender-Female & 0.80 & $0.38-0.71$ & 0.568 & & & \\
\hline $\begin{array}{l}\text { Age at disease onset } \\
\text { (years) }\end{array}$ & 0.97 & $0.95-0.99$ & 0.004 & 0.97 & $0.95-0.99$ & 0.026 \\
\hline $\begin{array}{l}\text { Disease duration at } \\
\text { recruitment (years) }\end{array}$ & 1.01 & $0.98-1.05$ & 0.504 & & & \\
\hline \multicolumn{7}{|l|}{ Organ involvements } \\
\hline $\begin{array}{l}\text { Skin \& mucous } \\
\text { involvement }\end{array}$ & 1.40 & $0.81-2.43$ & 0.230 & & & \\
\hline $\mathrm{LN}$ & 0.76 & $0.45-1.28$ & 0.298 & & & \\
\hline NPSLE & 0.74 & $0.29-1.85$ & 0.513 & & & \\
\hline AIHA & 1.10 & $0.64-1.87$ & 0.735 & & & \\
\hline Thrombocytopenia & 0.88 & $0.47-1.63$ & 0.683 & & & \\
\hline $\mathrm{PAH}$ & 1.13 & $0.35-3.62$ & 0.842 & & & \\
\hline \multicolumn{7}{|l|}{$\begin{array}{l}\text { Laboratories at } \\
\text { recruitment }\end{array}$} \\
\hline Anti-dsDNA positive & 1.43 & $0.82-2.5$ & 0.209 & & & \\
\hline $\mathrm{C} 3(\mathrm{mg} / \mathrm{L})$ & 0.996 & $0.995-0.998$ & 0.000 & 0.997 & $0.996-0.999$ & 0.001 \\
\hline UTP (mg) & 0.998 & $0.993-1.002$ & 0.450 & & & \\
\hline \multicolumn{7}{|l|}{ Treatments } \\
\hline $\begin{array}{l}\text { Prednisone or } \\
\text { equivalent dose at } \\
\text { recruitment }\end{array}$ & 1.00 & $0.99-1.02$ & 0.684 & & & \\
\hline IS for 6 months $5^{+\infty \infty \infty}$ & 1.21 & $0.57-2.58$ & 0.614 & & & \\
\hline $\begin{array}{l}\text { Percentage time of } \\
\text { LLDAS }\end{array}$ & 0.10 & $0.04-0.25$ & 0.000 & 0.18 & $0.07-0.48$ & 0.001 \\
\hline $\begin{array}{l}\text { "Years: disease du} \\
\infty \text { Present ever du } \\
\infty \infty 0 \text { Using immun } \\
€ \text { Percentage time } \\
\text { Abbreviations: L2 } \\
\text { PAH=pulmonar }\end{array}$ & $\begin{array}{l}\text { tition at recr } \\
\text { ng course of } \\
\text { uppressant } \\
\text { fLLDAS in } \\
\text { lupus neph } \\
\text { rterial hype }\end{array}$ & $\begin{array}{l}\text { tent defined as tin } \\
\text { lisease. } \\
\text { of } 6 \text { during whole fol } \\
\text { tole follow-up time } \\
\text { tis; NPSLE= neurop } \\
\text { tension. }\end{array}$ & rom disease o & et to recrui & aune hemolytic ar & emix; \\
\hline
\end{tabular}

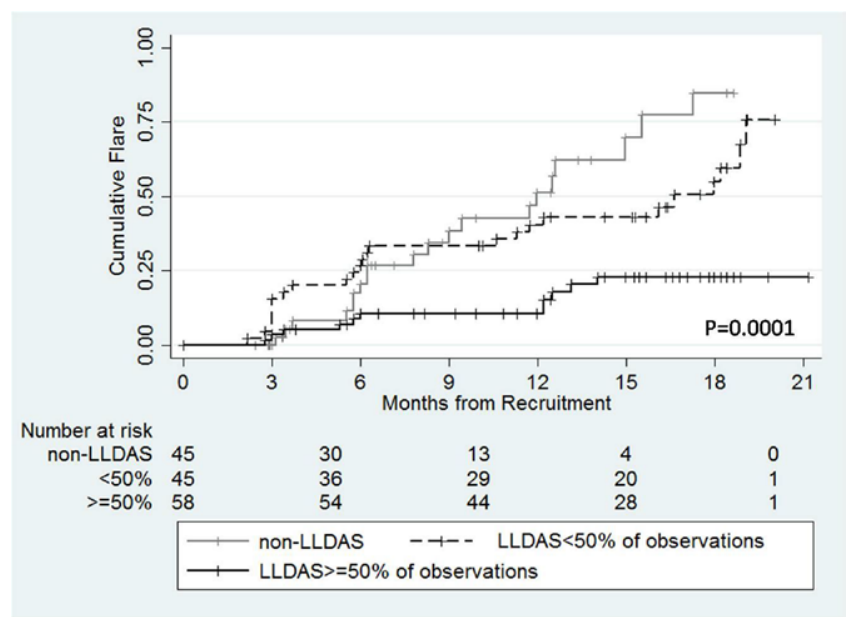

Methods: The baseline and follow-up data of all consecutive patients in a longitudinal lupus cohort from January 2017 to December 2018 were collected prospectively. SLEDAI-2K, PGA and disease flare were assessed at each follow-up visit, and further compared to the previous routine clinical visits. Irreversible disease damage was captured using the SLICC damage index and the short form (36) health survey for health-related quality of life was completed annually.

Results: One hundred and forty-nine patients were enrolled, with the median disease duration at recruitment of $2.4(0.9-8.2)$ years, and median follow-up of $15.4(10.1-18.2)$ months. By the end of the study, $104(69.8 \%)$ patients 
achieved LLDAS at least once; 59 patients achieved LLDAS for $\geq 50 \%$ of observations. Multivariate logistic regression analysis showed that age at disease onset $<30$ years $(\mathrm{OR}=0.05,95 \% \mathrm{Cl}$ [0.01-0.59], $\mathrm{p}=0.017)$, 24-hour urine total protein (UTP) level at recruitment $(\mathrm{OR}=0.9992,95 \% \mathrm{Cl}$ [0.99870.9998], $p=0.007)$, and C3 level (OR=1.004, 95\%Cl [1.001-1.008], $p=0.024)$ had independent associations with achieving LLDAS for $\geq 50 \%$ of all observations (Table 1). During follow-up, 56 (37.6\%) patients experienced disease flare including $14(9.4 \%)$ patients with severe flare. Kaplan-Meier analyses showed significant differences in flare rates according to whether LLDAS was achieved and the percentage follow-up time in LLDAS (Figure 1). Multivariate cox analysis revealed that the percentage time of time in LLDAS was an independent negative determinant of disease flare $(\mathrm{HR}=0.18,95 \% \mathrm{Cl}[0.07-$ 0.48 ], $p=0.001$ ) (Table 2). There were $16(15.0 \%) / 107$ patients who had damage accrual after one year of follow-up. Multivariate logistic analysis showed a tendency for achieving LLDAS during follow-up being protective for damage accrual (OR=0.27, 95\% $\mathrm{Cl}[0.07-1.00], \mathrm{p}=0.050)$.

Conclusion: In this Chinese early disease cohort, LLDAS was an attainable goal in clinical practice. Age at onset, UTP and C3 level at recruitment influenced achievement of LLDAS. LLDAS was negatively associated with disease flare and damage accrual; this needs to be confirmed by future longer follow-up.

Acknowledgments: The data in this cohort was collected and recorded using the framework of the lupus low disease activity status (LLDAS) study from the Asia-Pacific Lupus Collaboration (APLC).

Disclosure of Interests: Yanjie Hao: None declared, Lanlan Ji: None declared, Dai Gao: None declared, Yong Fan: None declared, Eric F. Morand Grant/ research support from: AstraZeneca, Consultant of: AstraZeneca, Speakers bureau: AstraZeneca, Mandana Nikpour: None declared, Zhuoli Zhang: None declared

DOI: 10.1136/annrheumdis-2020-eular.807

\section{AB0377 COMPUTATIONAL DISCOVERY AND PRECLINICAL VALIDATION OF THERAPEUTIC LEADS WITH NOVEL MOAS FOR SYSTEMIC LUPUS ERYTHEMATOSUS (SLE)}

I. Hakim ${ }^{1}$, S. Mujahid ${ }^{1}$, A. C. Daugherty ${ }^{1}$, T. S. Heuer ${ }^{1}{ }^{1}{ }^{1}$ woXAR, Inc, Mountian View, United States of America

Background: Lupus is a heterogeneous, systemic disease that affects millions of patients globally with a high unmet medical need. We present results from our powerful and efficient computational drug discovery platform that identifies hits with first-in-class mechanisms of action that can advance rapidly and successfully through preclinical validation studies. The twoXAR discovery platform uses an artificial-intelligence framework to integrate diverse patient-derived biomedical data sets to build holistic and unbiased models of human disease biology. The utilization of diverse, proprietary algorithms and deep learning principles provides a highly sensitive platform to elucidate complex disease-specific associations between biology and biomedical data that are integrated with a library of existing drug molecules. This enables the identification of novel, high-value drug discovery hits with known pharmacological properties. The twoXAR platform also preserves interpretable datadriven links to disease biology to facilitate efficient validation and optimization studies.

Objectives: Apply twoXAR's computational drug discovery platform for the discovery of first-in-class lupus therapy hits and perform preclinical characterization of selected hits to identify drug discovery lead molecules.

Methods: Using clinical SLE patient data, we employed the twoXAR platform to build an in-silico SLE disease model. Nine molecules with novel mechanisms of action (not previously tested as candidate clinical therapies for lupus) were identified as drug discovery hits and then characterized in preclinical efficacy studies using the MRL mouse model of lupus.

Results: In preclinical validation studies with the MRL mouse model, 2 compounds were differentiated by significant efficacy and excellent tolerability. TXR711 and TXR-712 increased renal function, decreased renal inflammation and decreased inflammation compared to vehicle-treated control mice. In particular, TXR-711 and TXR-712 significantly decreased serum blood urea nitrogen (BUN) levels, decreased proteinuria levels, and significantly improved kidney histology readouts such as glomerulonephritis and tubule basophilia. Additionally, TXR711 and TXR-712 treatment resulted in significantly decreased inguinal lymph node weight.

Conclusion: TXR-711 and TXR-712 were identified as SLE drug discovery leads with novel MOAs for further preclinical development. Ongoing studies with
TXR-711 and TXR-712 includes pharmacokinetic, pharmacodynamic, and additional MRL mouse efficacy characterization.

Disclosure of Interests: Isaac Hakim Employee of: twoXAR, Inc, Sana Mujahid Employee of: twoXAR, Inc., Aaron C. Daugherty Employee of: twoXAR, Inc., Timothy S. Heuer Employee of: twoXAR, Inc

DOI: 10.1136/annrheumdis-2020-eular.2920

\begin{tabular}{l|l}
\hline AB0378 & UPGRADING THERAPY STRATEGY IMPROVES \\
PREGNANCY OUTCOME IN ANTIPHOSPHOLIPID \\
SYNDROME: A COHORT MANAGEMENT STUDY
\end{tabular}

A. Hoxha ${ }^{1,2}$, M. Favaro ${ }^{1}$, A. Calligaro ${ }^{1}$, T. Del Ross ${ }^{1}$, A. T. Ruffatti ${ }^{3}$, C. Infantolino ${ }^{3}$, M. Tonello ${ }^{1}$, E. Mattia ${ }^{1}$, A. Ruffatti ${ }^{1}$. ${ }^{1}$ University of Padua, Department of Medicine-DIMED, Padua, Italy; ${ }^{2}$ San Bortolo Hospital, Department of Medicine, Vicenza, Italy; ${ }^{3}$ University-Hospital of Padua, Obstetrics and Gynaecology Unit, Padua, Italy

Background: While it is generally agreed that pregnant APS patients should receive personalized treatment, evidence-based guidelines for these patients continue to be lacking.

Objectives: The current study was designed as a management cohort study aiming to evaluate the efficacy and safety of different treatment strategies for pregnant APS patients in the attempt to provide some practical suggestions for attending physicians.

Methods: One-hundred-twenty-seven consecutive pregnancies were assessed; 87 (68.5\%) with a history of pregnancy morbidity alone were treated with prophylactic low molecular weight heparin (LMWH)+low-dose aspirin (LDA, $100 \mathrm{mg}$ ) [Group I] and 40 (31.5\%) with a history of thrombosis and/ or severe pregnancy complications with therapeutic LMWH+LDA [Group II]. $\mathrm{LMWH}$ doses were increased throughout the pregnancies depending on the patients' weight gain, and treatment was switched to a more intensive one at the first sign of maternal/fetal complications. The study's primary outcome was live births.

Results: There were no significant differences in live birth rate between Group I $(95.4 \%)$ and Group II (87.5\%). Even, fetal complication rate was similar in the two groups; the Group II nevertheless had a higher prevalence of maternal and neonatal complications $(p=0.0005$ and $p=0.01$, respectively) and registered a significantly lower gestational age at delivery and birth weight ( $p=0.0001$ and $p=0.0005$, respectively). Two patients in Group I switched to Group II therapy, six patients in Group II switched to a more intensive treatment strategy (weekly plasma exchange+ fortnightly intravenous immunoglobulins in addition to therapeutic LMWH+LDA). Comparison of the clinical and laboratory characteristics between patients who had shifted to a more intensive therapy and those who did not showed a significant prevalence of history of thrombosis \pm pregnancy morbidity $(p=0.02$, OR $5.96,95 \% \mathrm{Cl} 1.33-26.62)$ previous pregnancy complications ( $p=0.02$, OR $8.32,95 \% \mathrm{Cl} 1.67-41.3)$, triple aPL positivity ( $\mathrm{p}<0.0001$, OR $97.13,95 \% \mathrm{Cl} 10.6-890)$ and pregnancy complications ( $p<0.0001$, OR $197,7,95 \% \mathrm{Cl} 10.57-3699)$ in upgrading group, instead single aPL positivity significantly prevailed $(p=0.003$, OR $0.06,95 \% \mathrm{Cl} 0.008$ 0.58 ) in non-upgrading group. Logistic regression analysis demonstrated that triple aPL positivity was an independent factor for switching to a more effective therapy protocol ( $p<0.0001$, OR $98,95 \% \mathrm{Cl} 10.7-897.54)$. All eight switched patients achieved a live birth.

Conclusion: Using adjusted LMWH doses and upgrading therapy at the first signs of pregnancy complications led to a high rate of live births in a relatively large group of APS patients. The study outlines the criteria for prescribing appropriate therapy for various subsets of these patients and for switching/upgrading the treatment protocol when it is no longer sufficient. Unfortunately, for the moment there are no evidence-based guidelines on the ideal additional treatment in refractory to conventional therapy APS patients. The present results will hopefully help point the direction of future clinical trials investigating the efficacy and safety of the different therapies on large numbers of APS pregnant patients in order to identify the benefits and limits of different treatment strategies administered from the beginning of pregnancy.

Disclosure of Interests: Ariela Hoxha Speakers bureau: Celgene, UCB, Novartis, Sanofi, Werfen, Maria Favaro: None declared, Antonia Calligaro: None declared, Teresa Del Ross: None declared, Alessandra Teresa Ruffatti: None declared, Chiara Infantolino: None declared, Marta Tonello: None declared, Elena Mattia: None declared, Amelia Ruffatti: None declared DOI: 10.1136/annrheumdis-2020-eular.2704 